\title{
ALGUNAS PALABRAS FINALES ${ }^{1}$
}

\section{Orin Starn}

NUNCA IMAGINÉ que este artículo provocaría tanta indignación e ira $^{2}$. Lo escribí en 1989 como un intento serio y honesto de hablar de lo que me parecían algunos problemas significativos en la manera en que muchos antropólogos habíamos concebido la experiencia de los campesinos andinos. En esta breve intervención quisiera responder a los comentaristas y ofrecer unas reflexiones finales sobre el debate.

Reconozco dos limitaciones del ensayo. Una es mi inadecuada atención a las tradiciones nacionales de la antropología en los paises andinos. Como precisan Thurner y Salomon, mi ensayo se concentra en los norteame-

1 Esta respuesta ha sido hecha en base a los primeros borradores de los comentarios que recibí de los editores de Allpanchis a mediados de 1991.

2 Para otra respuesta encolerizada véase el reciente ensayo de Enrique Mayer en Cultural Anthropology (rioviembre, 1991). Con muchas disculpas a los lectores de Allpanchis que no hayan visto el ensayo, voy a aprovechar este espacio para responderle también a Mayer. 


\section{ORIN STARN}

ricanos. Siempre han existido intensas interconexiones intelectuales $e$ institucionales entre las antropologías de Norteamerica, Europa y Latinoamerica. Obviamente, sin embargo, las genealogías de la disciplina en cada lugar tienen sus propias idiosincracias. La falta de sensibilidad a las particularidades de las antropologías peruanas, bolivianas, colombianas, y ecuatorianas da un elemento de anglocentrismo al ensayo.

Un segundo problema con mi análisis es su tendencia a sobreestimar la aceptación de SL en la sierra. Todavía persisten corrientes de apoyo para los seguidores de Guzmán en muchos caseríos en las zonas de emergencia. Pero han perdido mucha de la simpatía más generalizada que gozaban entre 1980-82 en Ayacucho y luego en su ofensiva de 1988-1989 en Junín. El crecimiento de rondas de autodefensa en la sierra sur-central refleja, en parte, el desencanto con el autoritarismo de Sendero ${ }^{3}$. Los importantes estudios recientes de Coronel y Loayza, del Pino y de Manrique nos ofrecen una visión cercana de los problemas de los maoístas en diferentes zonas de la sierra ${ }^{4}$. Mi análisis se habría beneficiado de una mayor atención a las complejas dinámicas de los reveses que han obligado a Sendero a reformular su plan inicial de cercar las ciudades en base al apoyo del campesinado.

3 Para más información sobre estas organizaciones, véase Instituto de Defensa Legal. "El papel de la organización campesina en la estrategia antisubversiva" (1991, mimeo). Orin Starn. "Sendero, Soldados y Ronderos en el Mantaro (1991, Quehacer 74) y los abajo mencionados ensayos de Coronel y Loayza y del Pino.

4 José Coronel Aguirre y Jorge Loayza Camargo, "Violencia política: Formas de respuesta comunera en Ayacucho" (SEPIA, 1991); Ponciano del Pino. "Los campesinos en la guerra: Una aproximación a los Comités de Defensa Civil a partir de un espacio rural" (SEPIA, 1991); Nelson Manrique, "La década de la violencia" (Márgenes 5-6, 1991). Para una reseña del estado actual de la literatura sobre Sendero, véase Orin Starn, "New Literature on Peru's Sendero Luminoso" (Latin American Research Review, marzo, 1992) y la introducción de Carlos Iván Degregori al presente número de Allpanchis. 
A pesar de estas limitaciones, sigo completamente convencido que el argumento básico del ensayo es correcto. Invito a los lectores de Allpanchis a hojear la literatura etnográfica de los 60 y $70^{5}$. En vez de menos, creo que saldrán más persuadidos respecto de que muchos antropólogos tendían a mantener el mito de un discreto y eterno "mundo andino" y hacer caso omiso al abundante descontento político en la sierra.

En vez de ofrecer una evaluación sensata del ensayo, cuatro de los comentaristas toman una posición de denuncia y rechazo. Linda Seligmann y Enrique Mayer me culpan por exagerar el "andinismo" de la antropología de los 60 s y 70 s. Ignoran que el ensayo siempre es clarísimo en reconocer las múltiples maneras a través de las cuales muchos antropólogos se distanciaban del concepto de una invariable y homogenea "tradición andina". Si no incluí la cita de Reciprocidad e intercambio, no fue para sugerir que Mayer y Alberti o cualquier otro estudioso fueran insensibles a muchos de los constantes cambios en la vida andina desde la llegada de Pizarro. Al contrario, el párrafo anterior enfatiza la ya creciente sensibilidad a la historia en la antropología de los 60 s y 70 s. Lo que sí quería mostrar era la proliferación en el discurso etnográfico de imágenes orientalistas que presentaban la sierra en términos de una yuxtaposición entre un estático y tradicio-

5 Todavia no había llegado el comentario de Juan Ansión al momento de redactar esta respuesta. En base a su título un poco despectivo, dudo que estare muy de acuerdo con su lectura. Cabria decir que no creo que las casi uniformemente negativas evaluaciones de los comentaristas en Allpanchis den una muestra enteramente representativa de la recepción del ensayo. Varias cartas y comentarios personales me dan la impresión que hay por lo menos una minoría significativa de lectores que lo han encontrado con algo de utilidad $y$ valor. Junto con el ensayo de Mayer, será reeditado en un nuevo libro de ensayos seleccionados de Cultural Anthropology (Duke University Press, 1992, editado por George Marcus). 


\section{ORIN STARN}

nal "ellos" y un avanzado y moderno "nosotros"6. Mayer asevera en su comentario que hablar de la sobrevivencia de valores incaicos no es nada diferente que hablar de la preservación de la costumbre pagana del árbol de navidad en los EE.UU. ¡Hablemos en serio! Las referencias abundantes a immutables tradiciones andinas en el trabajo de Zuidema, Skar, Bastien y tantos otros iba mucho más allá de la por supuesto aceptable afirmación que todos conservamos lazos con el pasado. Como intenté mostrar en el ensayo, reflejaba la propagación parcial entre los antropólogos de una visión de campesinos como parroquianos tradicionalistas, que subestimaba seriamente el impacto de la intensificación de la migración, la extensión de redes de comunicación masiva, la masificación de la alfabetización y las otras grandes $e$ interrelacionadas transformaciones de la sierra a través del siglo XX.

Por su parte, Deborah Poole y Gerado Rénique construyen su condena condescendiente en base a distorsiones desvergonzadas. Se refieren a "numerosos errores factuales" sin dar un sólo ejemplo. Dejan la falsa impresión de que yo estuviera aseverando que los antropólogos

6 Siguiendo el trabajo del antropólogo norteamericano Richard Fox (Gandhi's Utopia, Beacon Press 1990) sobre el "orientalismo" en representaciones de la India, se puede distinguir entre "andinismo negativo" y "andinismo afirmativo". Muchas veces ligadas a antiguas visiones racistas de la inferioridad de la gente de la sierra, el "andinismo negativo" representa a lo andino como un estigma que obstaculiza el progreso. En contraste, el "andinismo afirmativo" presenta a la cultura andina como algo noble a ser defendido contra el avance de la modernidad. Las implicaciones politicas de estos dos tipos de andinismos son diferentes. Pero comparten la presuposición que los campesinos contemporáneos pueden ser vistos como representantes de puros y primordiales valores andinos. Irónicamente, ninguna marca del andinismo ha llegado a tener mucha presencia en las auto-concepciones de los mismos agricultores de la sierra, quienes, por complejas razones históricas, han llegado a preferir identificarse en términos no étnicos como "campesino" o "peruano". 


\section{Palabras finales}

podrian haber previsto el crecimiento de $\mathrm{SL}^{7}$. Pasan por alto mi reconocimiento explícito de la importante contribución de los antropólogos a un mayor aprecio de tradiciones serranas para hacer su absurda aseveración de la "absoluta preferencia de Starn por la denuncia sobre cualquier texto, discurso o posición política que implique celebración o reivindicación de los valores culturales andinos" 8 . Hasta los encolerizados Mayer y Seligmann admiten que concuerdan con partes de mi análisis. Poole y Rénique prefieren deshecharlo por completo en un tono de aplomo engreido que desmiente la combinación de verdades a medias y falsedades abiertas de mucho de su comentario.

En general, el intento de Poole y Renique de historicizar mi ensayo es un fracaso risible. ¿Yupificado carácter de "Wall Street"??. Escribí el ensayo siendo un estudiante desempleado. ¿Desinteresado en la política? Todos mis años de trabajo en la sierra han sido sobre movimientos campesinos. ¿Elitismo vanguardista? Veáse cualquier artículo de Deborah Poole para una muestra verdadera de densa jerga académica. ¿Autoritarismo moral? Son Poole y Rénique quienes califican de "racista" $e$ "ideóloga política" a una estudiosa norteamericana, Cynthia McClintock, que ha trabajado por muchos años en la defensa de los

7 El párrafo final de su comentario ignora por completo que enfatizo desde el principio que sería injusto culpar a los antropólogos por no haber previsto el crecimiento de SL. Mi ensayo se basa en el muy distinto argumento que muchos etnógrafos eran insensibles a algunas de las condiciones detrás del desarrollo de la insurrección.

8 En otra distorsión, Poole y Rénique presentan una bibliografía de estudios sobre movimientos campesinos hecha por sociológos, historiadores y politólogos como si esto desacreditara mi argumento que los antropólogos de los 60 y los 70 no hacian mucho caso al fermento politico en el campo.

9 "Yuppie" se refiere en los EE.UU. a jóvenes profesionales urbanos. 
derechos humanos en el Perú10. Ya son más de quince años desde la publicación de trabajos como La Arqueología del Conocimiento, Metahistoria, y Orientalismo ${ }^{11}$. No es ninguna novedad decir que debemos situar la producción del conocimiento en su contexto social, institucional y político. El reto es hacerlo de una manera cuidadosa y constructiva, cosa que parece escapar por completo del trabajo de Poole y Rénique con su afición por caricaturas simplistas $e$ intolerantes.

¿Para qué, entonces, han servido mi ensayo, los comentarios, y ahora esta respuesta? En parte, para nada. Hay algo un poco grotesco en el espectáculo de una riña entre académicos en un momento que tanta gente en la sierra y en los pueblos jóvenes vive en medio de la pobreza y el terror. Uno de los objetivos principales de mi ensayo era empujar a los antropólogos -especialmente a mis colegas norteamericanos- hacia un mayor compromiso en la lucha por la justicia y la paz. Por lo menos en base a los comentarios, esto no parece haber sido logrado. Las contribuciones de Salomon y Thumer tienen un sentido de distancia emocional con los problemas actuales del Perú. Mayer, Poole y Rénique y Seligmann escriben con más pasión, pero dirigida principalmente a ventilar su furia contra un ensayo que intentaba contribuir a una necesaria y hasta atrasada ampliación del debate sobre las ópticas

10 Véase Deborah Poole y Gerardo Rénique. "The New Chroniclers of Peru: U.S. Scholars and their "Shining Path" of Peasant Rebellion" (1991, Bulletin of Latin American Studies, 134,176). Poole y Rénique satanizan a McClintock como sirviente del imperialismo norteamericano. Entre los muchos problemas obvios con este argumento está el hecho que McClintock ha colaborado por muchos años con Americas Watch y es mienbro de la junta directiva de la Oficina de Washington para Latinoamerica (WOLA), dos organizaciones que han encabezado la lucha contra la política de militarización en el Perú del gobierno norteamericano.

1 Michel Foucault, "The Archeology of Knowledge" (Harper Colophon, 1972); Hayden White, "Metahistory" (Johns Hopkins University Press, 1973); Edward Said, "Orientalism" (Vintage Books, 1978). 


\section{Palabras finales}

interpretätivas $y$ las posiciones politicas y morales de los antropólogos que trabajamos en la sierra.

$\mathrm{Si}$ algo bueno ha salido del debate, quizás ello sea un incremento en nuestra reflexividad sobre cómo representamos a los campesinos andinos. La configuración del mundo contemporáneo con su economía inteconectada, comunicaciones instantáneas $e$ incesante tráfico intercultural ha forzado a los antropólogos a abandonar nuestros conceptos antiguos de las sociedades indigenas y campesinas como entidades estáticas y auto-contenidas ${ }^{12}$. Sin embargo, una hojeada por varios trabajos recientes sobre los Andes revela, a su vez, que el deseo de imaginar a los campesinos como los herederos de una ininterrumpida y homogénea tradición indígena no ha desaparecido por completo ${ }^{13}$. Sólo al deshacernos de los últimos vestigios del "andinismo" vamos a poder comprender el dinamismo y la diversidad de las complejas visiones culturales y politicas del campesinado en medio de las condiciones de migración, violencia y crisis económica que caracterizan a los andes peruanos en las entrañas del siglo $\mathrm{XXI}^{14}$.

En fin, ¿irritante pelea entre antropólogos gringos? ¿Debate que contribuye al entendimiento de la experiencia andina? ¿Algo de ambos? Termino aquí, dejando el juicio final al lector.

12 Para buenas introducciones a estos debates en la antropología norteamericana, véase Renato Rosaldo, "Culture and Truth: The Remaking of Social Analysis" (Beacon Press, 1989), James Clifford, "The Predicament of Culture" (Harvard University Press, 1988), el reciente número especial de Cultural Anthropology sobre la antropología y el espacio editado por Akhil Gupta y James Ferguson (marzo, 1992).

13 Véase, por ejemplo, varias de las contribuciones al reciente libro Cultura Andina Agrocéntrica (1992, PRATEC).

14 Para dos evaluaciones recientes de cómo los cambios de la última mitad del siglo XX están obligando a los antropólogos a reformular sus entendimientos de la sierra, véase Jurgen Golte, "Algunos problemas que merecerían la atención de una antropología peruana" (1992, mimeo) y Jaime Urrutia, "Las comunidades campesinas y la historia de los estudios de un mito del siglo $X^{n}$ (1992, mimeo). 